\title{
Metamaterial inspired triband offset feed rectangular monopole for wireless applications
}

PRASAD JONES CHRISTYDASS S ( $\nabla$ prasadjoness.ece@krct.ac.in )

K Ramakrishnan College of Technology https://orcid.org/0000-0001-9225-9666

\section{Gunavathi N}

National Institute of Technology Tiruchirappalli

\section{Research Article}

Keywords: Metamaterial, Monopole, Multiband, OCSRR, offset feed, Rectangular patch

Posted Date: May 6th, 2021

DOl: https://doi.org/10.21203/rs.3.rs-499727/v1

License: (c) (i) This work is licensed under a Creative Commons Attribution 4.0 International License. Read Full License 


\section{Abstract}

A rectangular monopole engraved with an open complementary split-ring resonator (OCSRR) metamaterial is designed and proposed for multiband radio applications. The proposed antenna has a rectangular monopole feed with offset microstrip feed, and the OCSRR designed at $3.14 \mathrm{GHz}$ is engraved in the radiating element. The OCSRR is a special type of metamaterial with small electrical size. The OCSRR modifies the current direction due to its negative permittivity, which creates another resonance at $3.16 \mathrm{GHz}$. The left offset feed and abridged ground length creates another resonance at $3.82 \mathrm{GHz}$ and responsible for good impedance matching are achieved in all the resonating bands. The entire antenna is designed and fabricated on the FR4 substrate with a complete measurement equal to $27.84 \mathrm{~mm} \times 23.25$ $\mathrm{mm} \times 1.6 \mathrm{~mm}$. The proposed structure shows the multiband characteristics at $3.16 \mathrm{GHz}, 3.82 \mathrm{GHz}$, and $5.14 \mathrm{GHz}$ with a $\mathrm{S} 11$ of $-19.83 \mathrm{~dB},-17.90 \mathrm{~dB}$, and $-55.73 \mathrm{~dB}$, respectively. The critical parameters of the OCSRR are decided using the parametric analysis, and the simulated results are presented. The OCSRR negative permittivity extraction is done with NRW wave guide extraction method, and the result is validated with the help of OCSRR resonant frequency calculation. The uniformity is well maintained between the measured and simulated results. The multiband characteristics, reasonable gain, compactness, low design complexity, and small size are the significant features of the proposed antenna

\section{Full Text}

This preprint is available for download as a PDF.

\section{Figures}
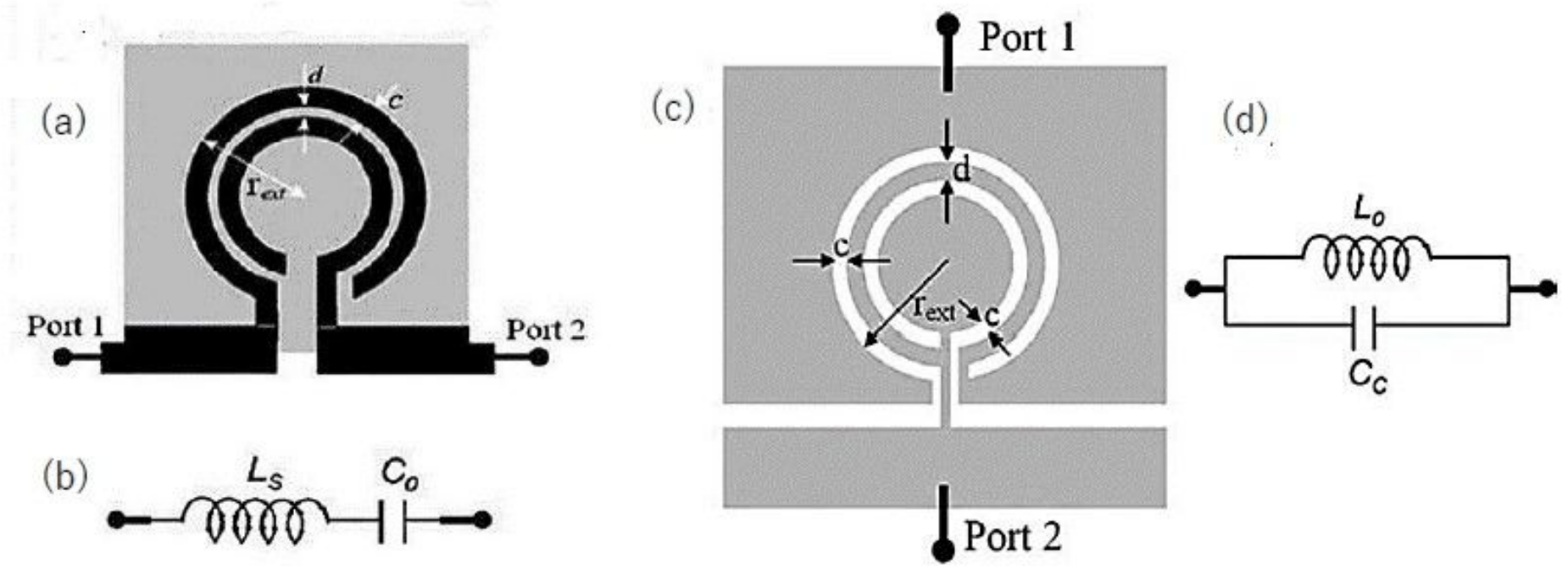

\section{Figure 1}

(a) OSRR topology (b) Equivalent circuit of OSRR (c) OCSRR topology (d) Equivalent circuit of OCSRR 

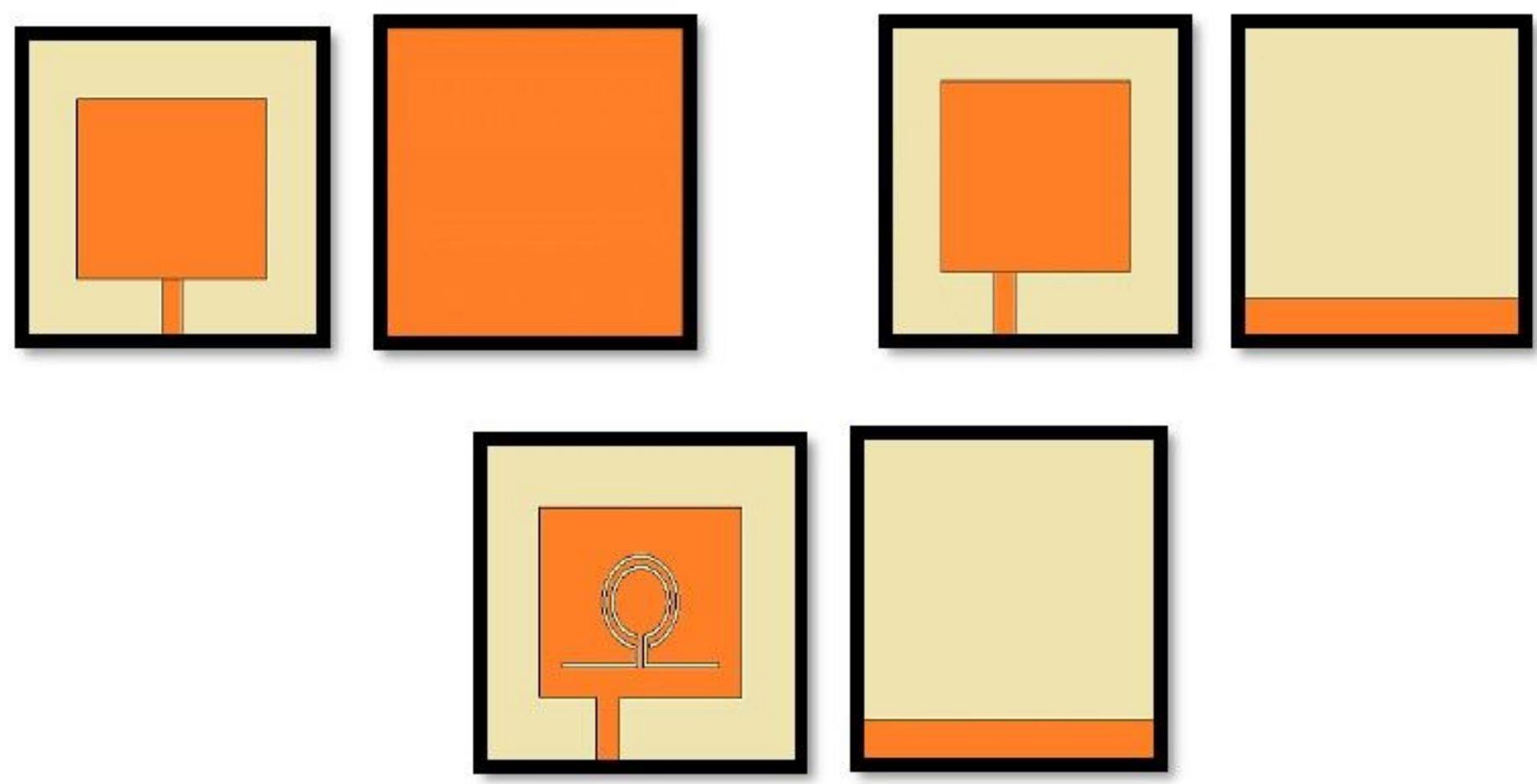

Figure 2

Design stages of OCSRR inspired rectangular printed antenna
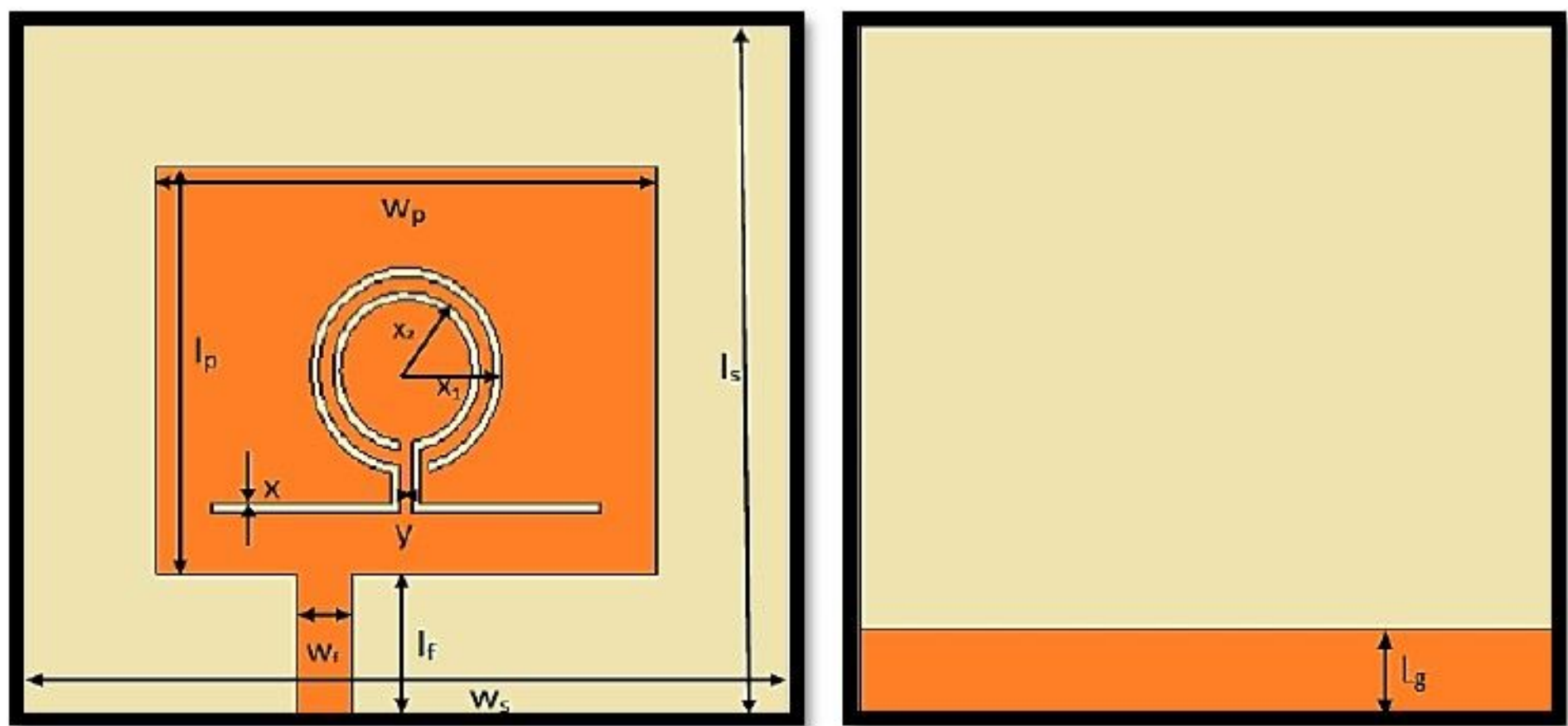

Figure 3

Front and Back View of OCSRR inspired rectangular printed antenna geometry 


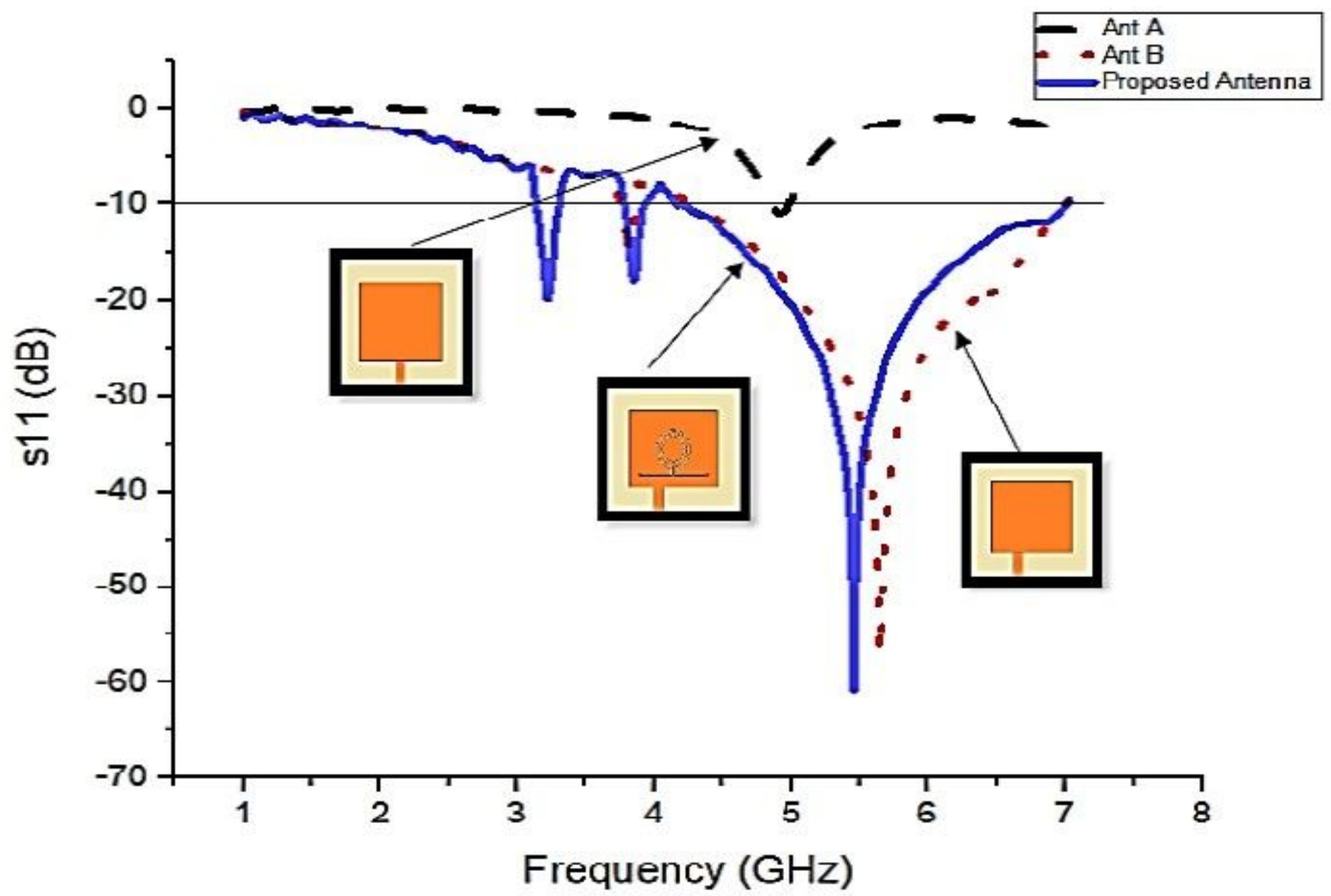

Figure 4

S11 Comparison (Ant A vs Ant B vs Proposed Antenna) 


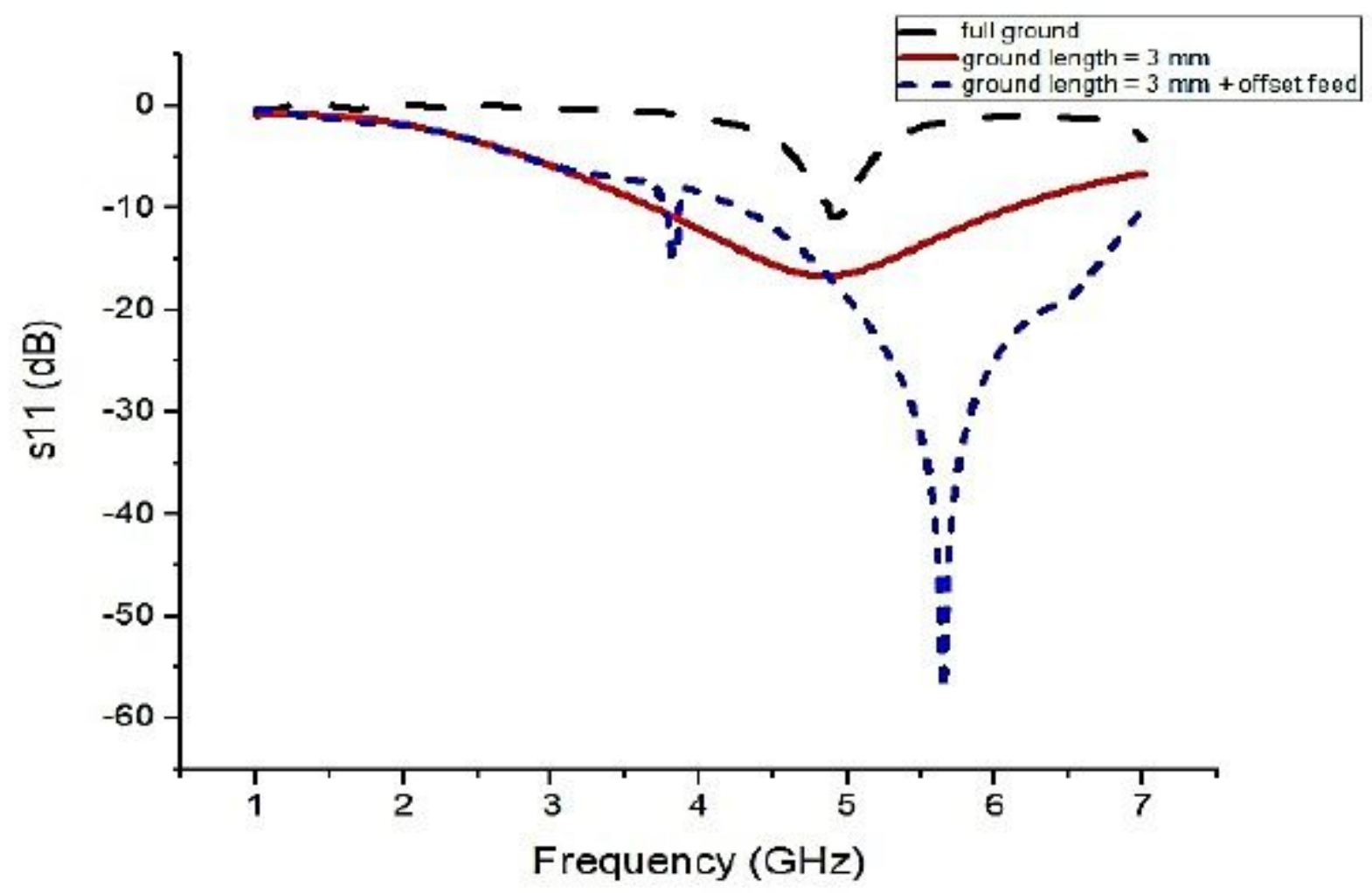

Figure 5

Return loss (simulation) Comparison of various ground length

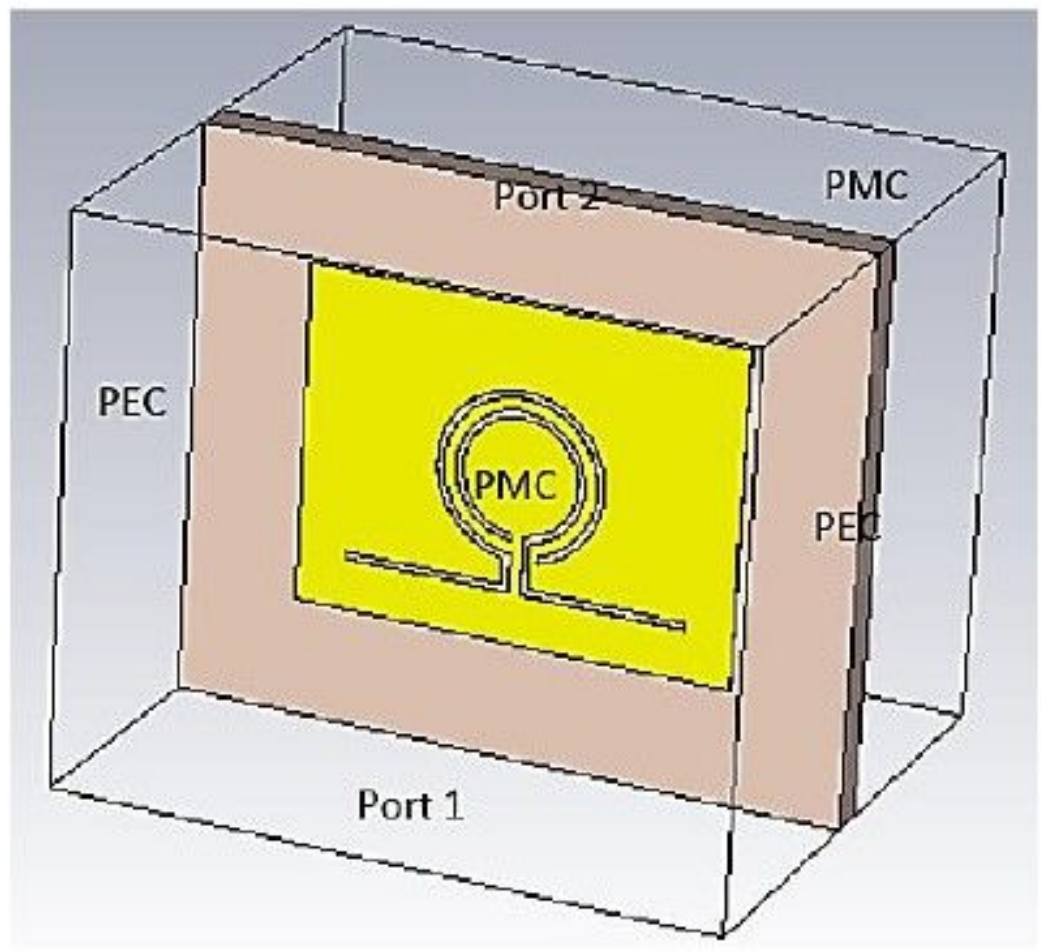

Figure 6 
Waveguide setup - permitivitty extraction

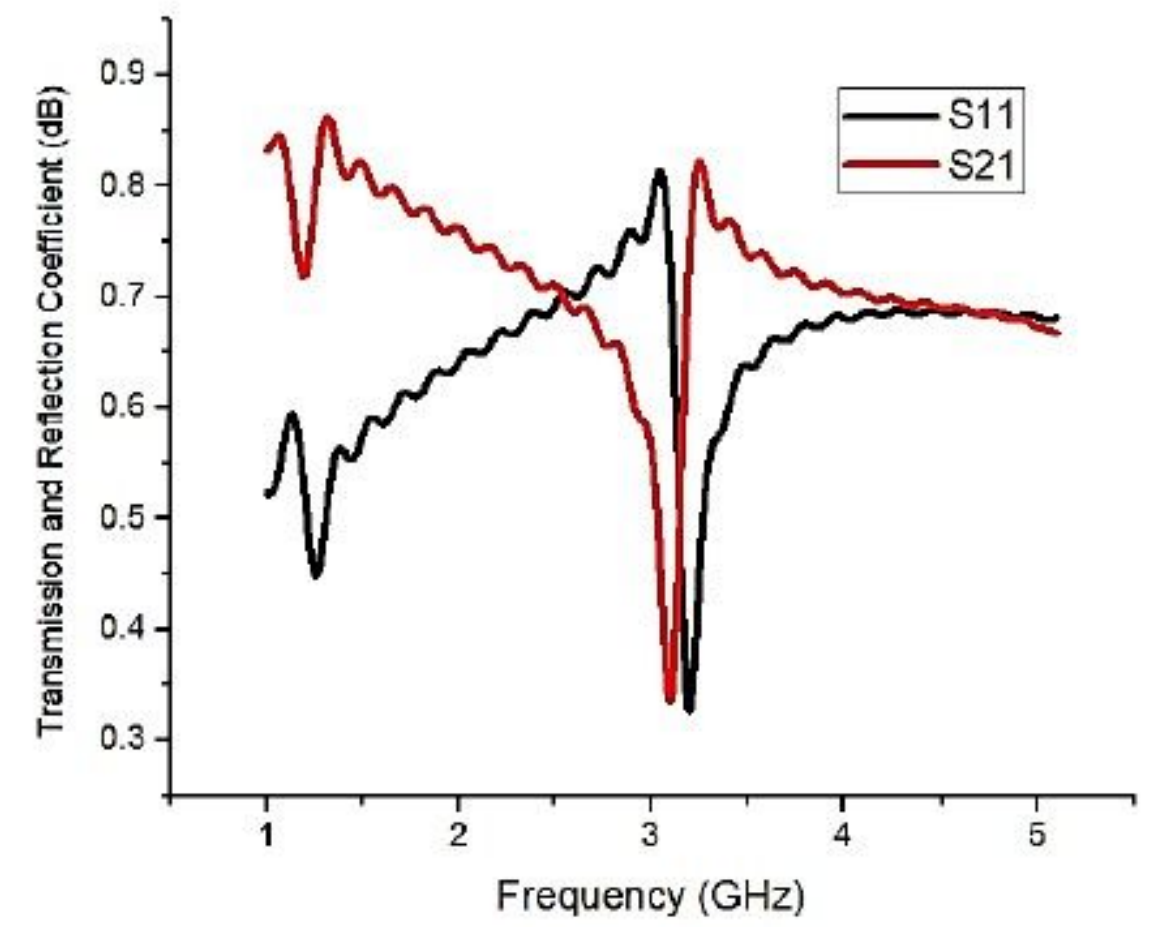

Figure 7

s11 \& s21 - characteristics of OCSRR

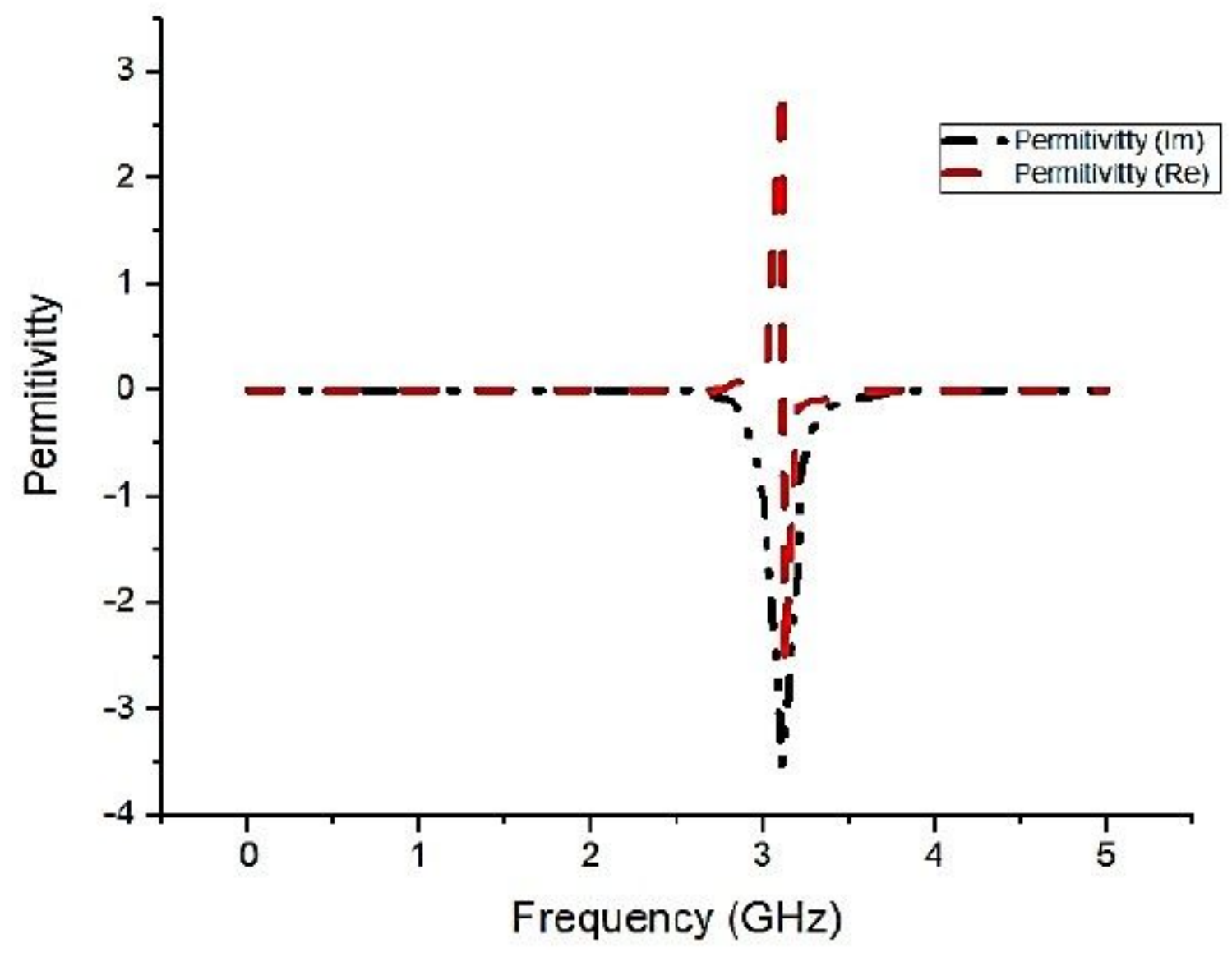


Figure 8

Permitivitty Characteristics of proposed OCSRR

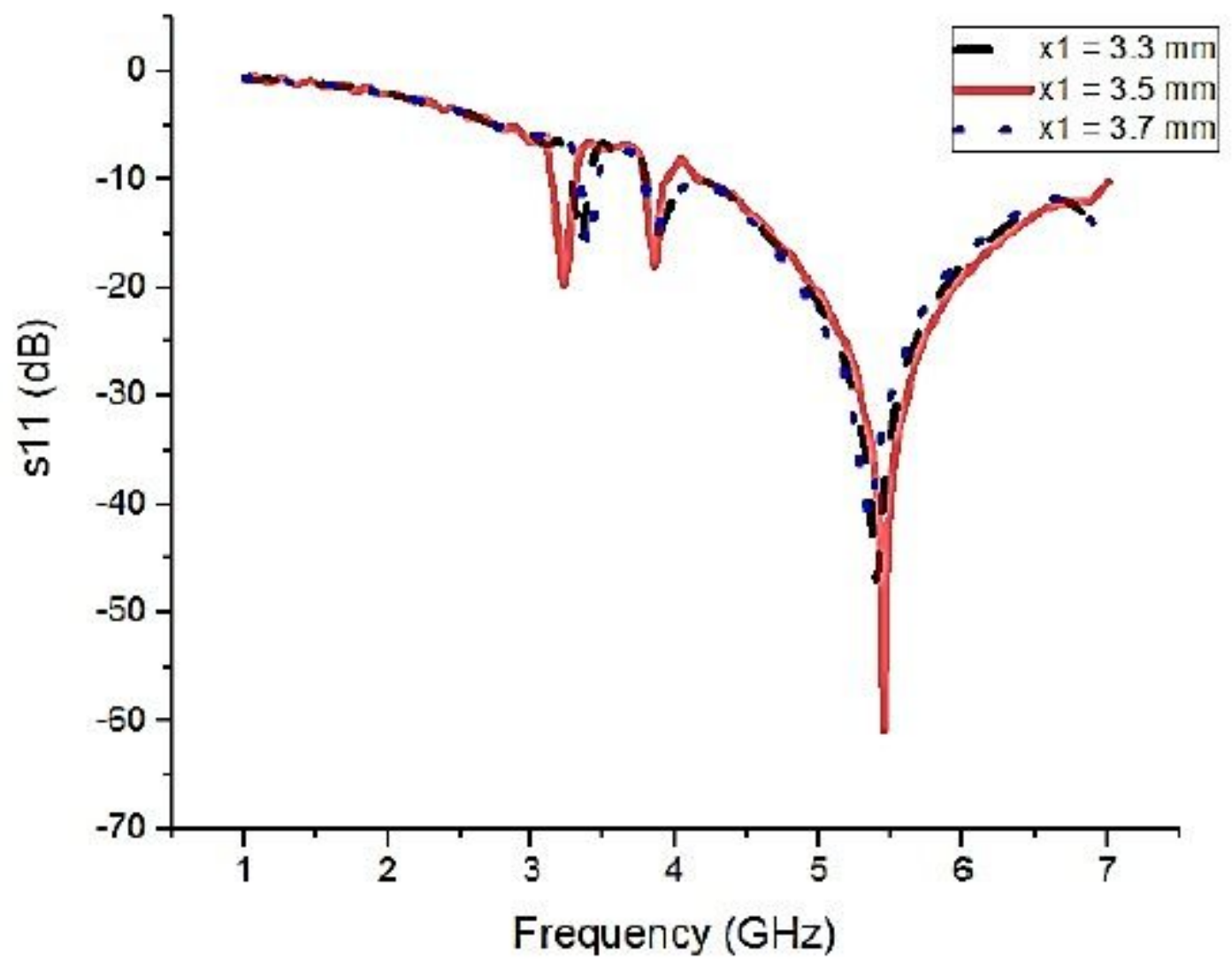

Figure 9

s11 evaluation for different values of $x 1$ 


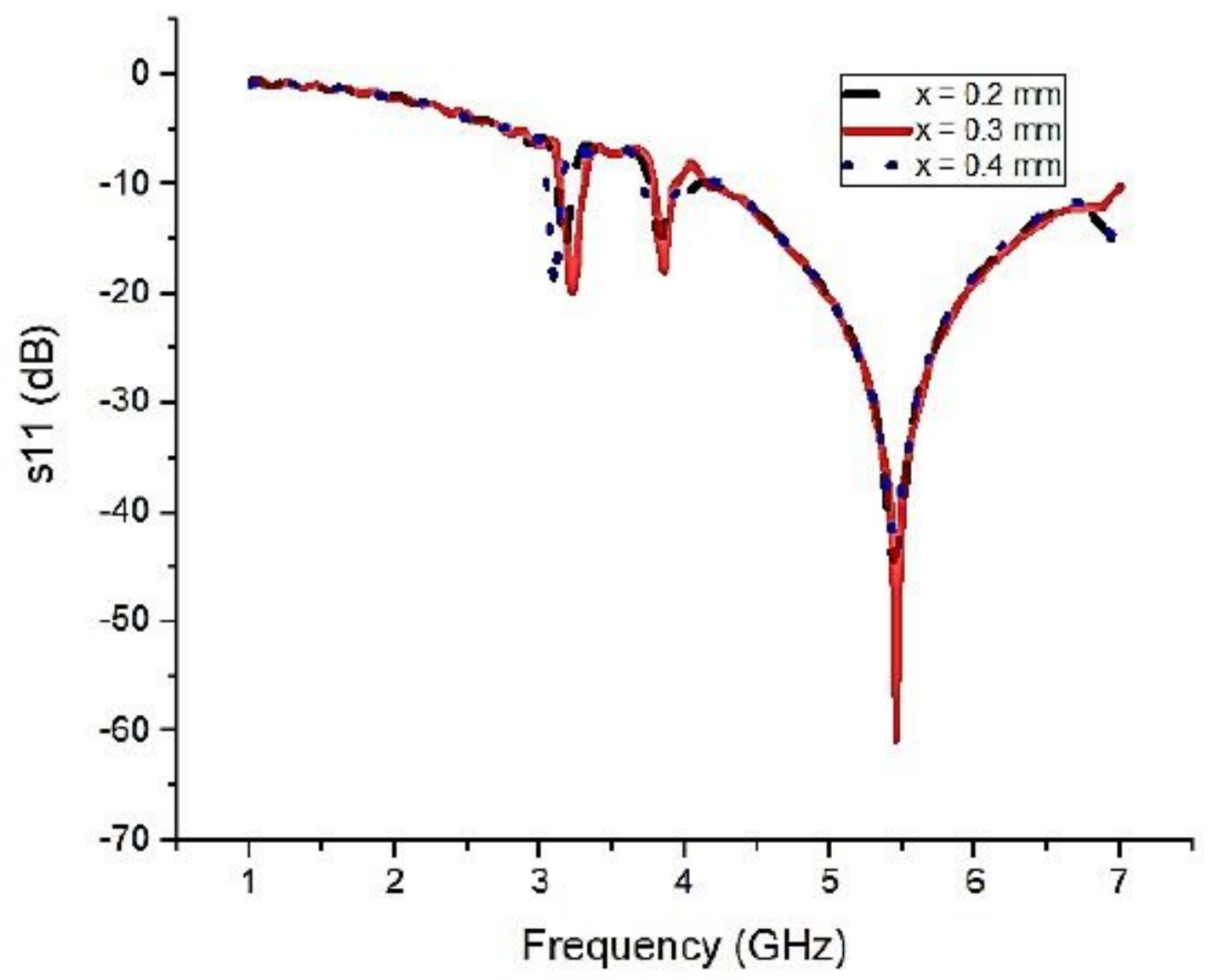

Figure 10

$s 11$ evaluation for different values of $x$ 


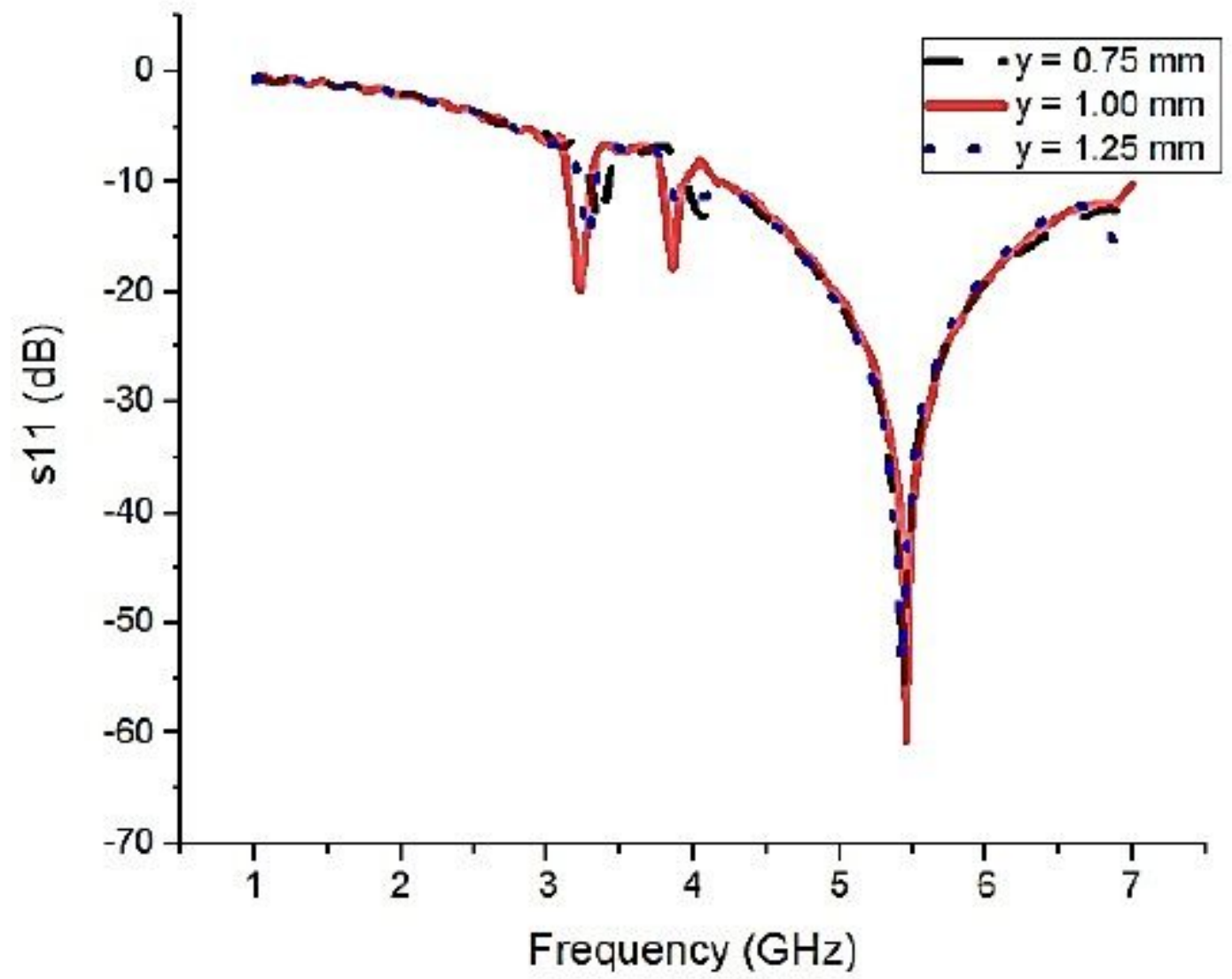

Figure 11

s11 evaluation for different values of $y$
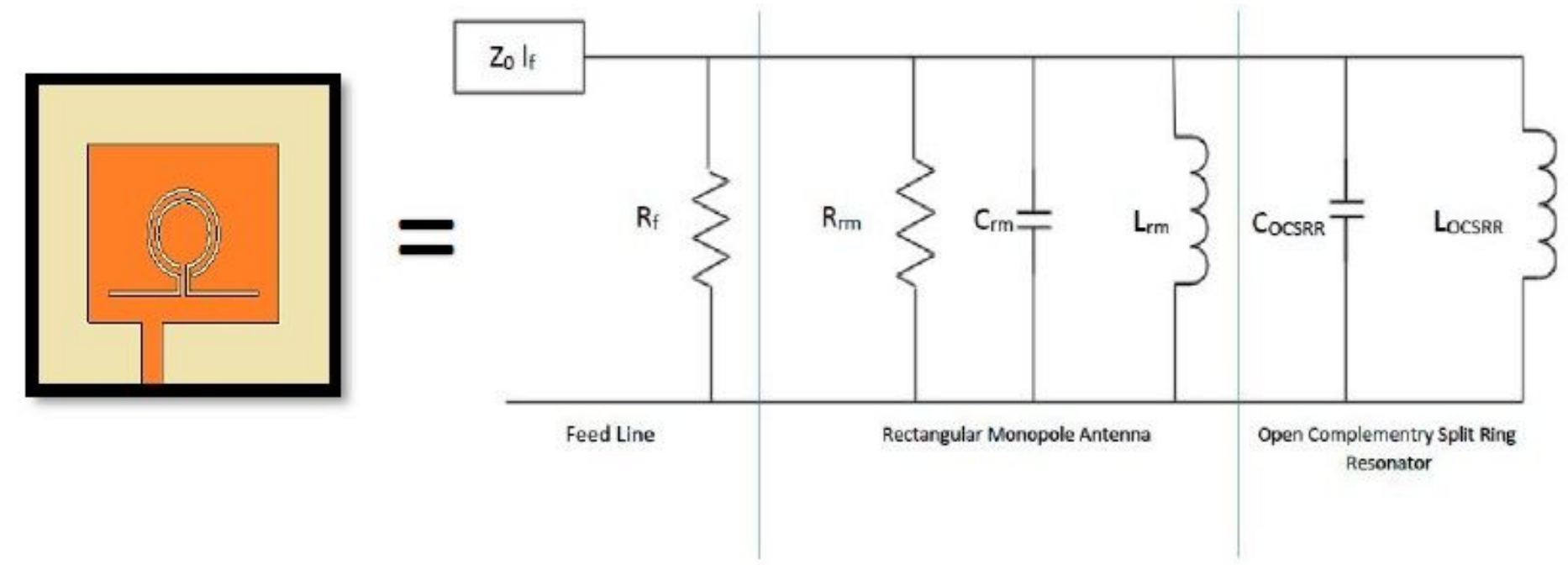

Figure 12

OCSRR inspired rectangular printed antenna equivalent circuit 


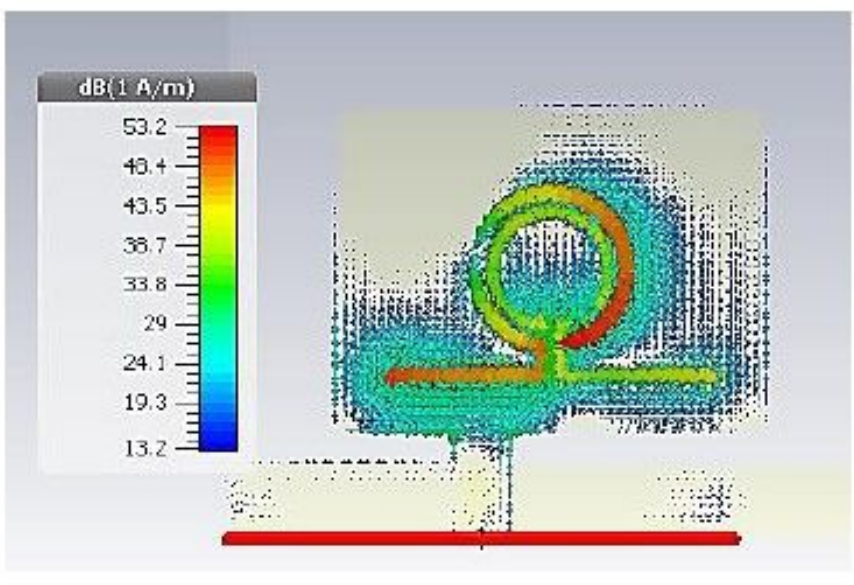

a) $3.16 \mathrm{GHz}$

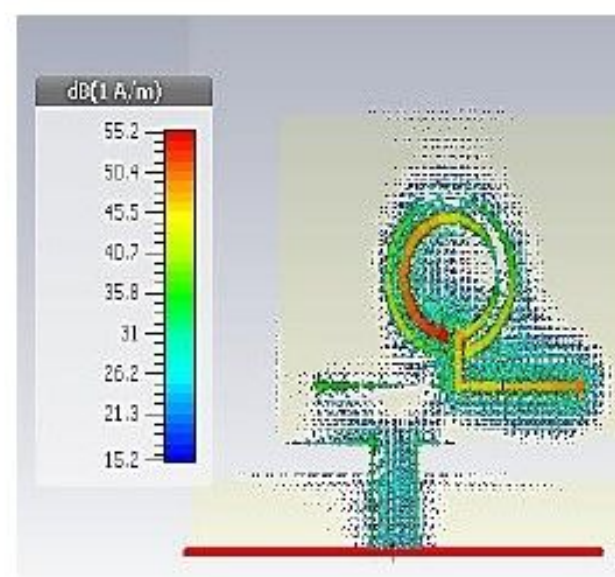

b) $3.82 \mathrm{GHz}$

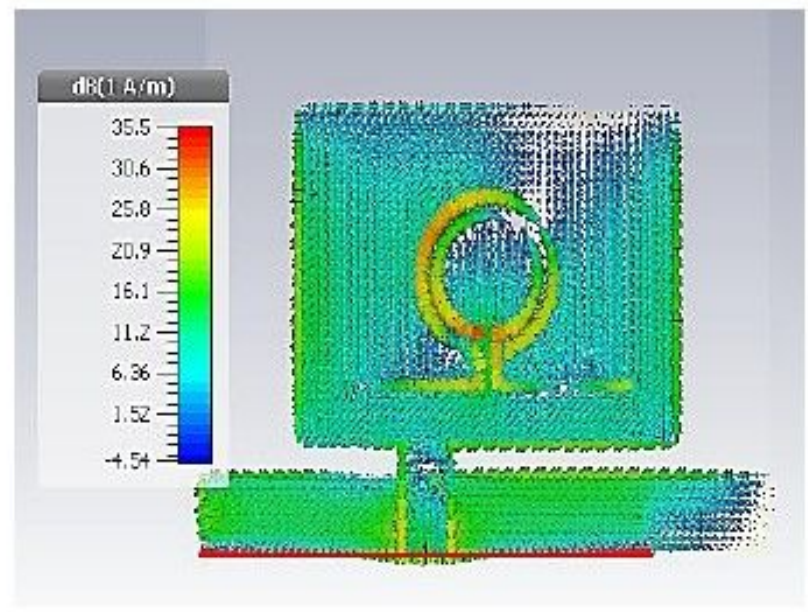

c) $5.41 \mathrm{GHz}$

Figure 13

Surface current distribution at resonating frequency 


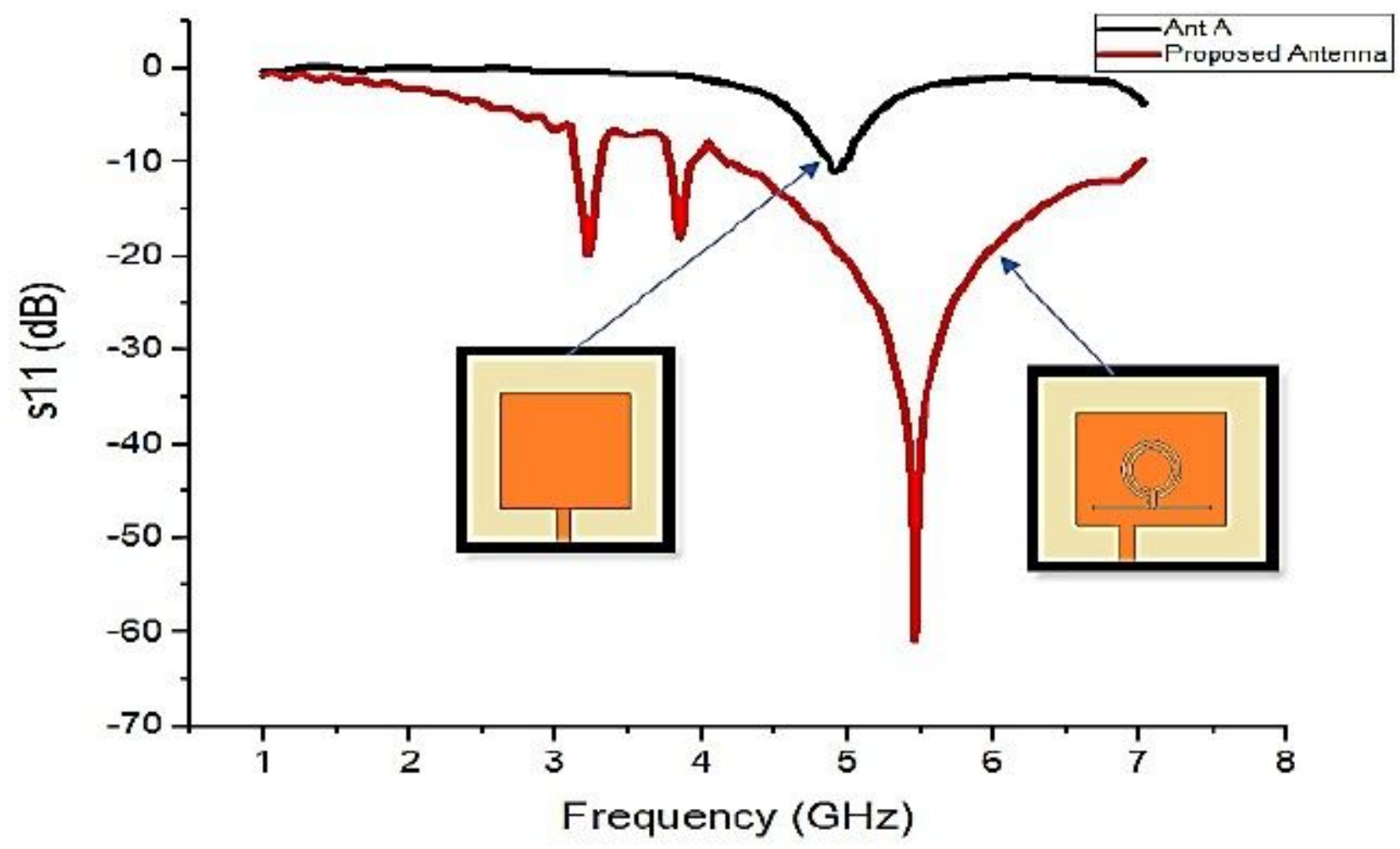

Figure 14

Return loss Comparison of the Ant A and Proposed antenna 


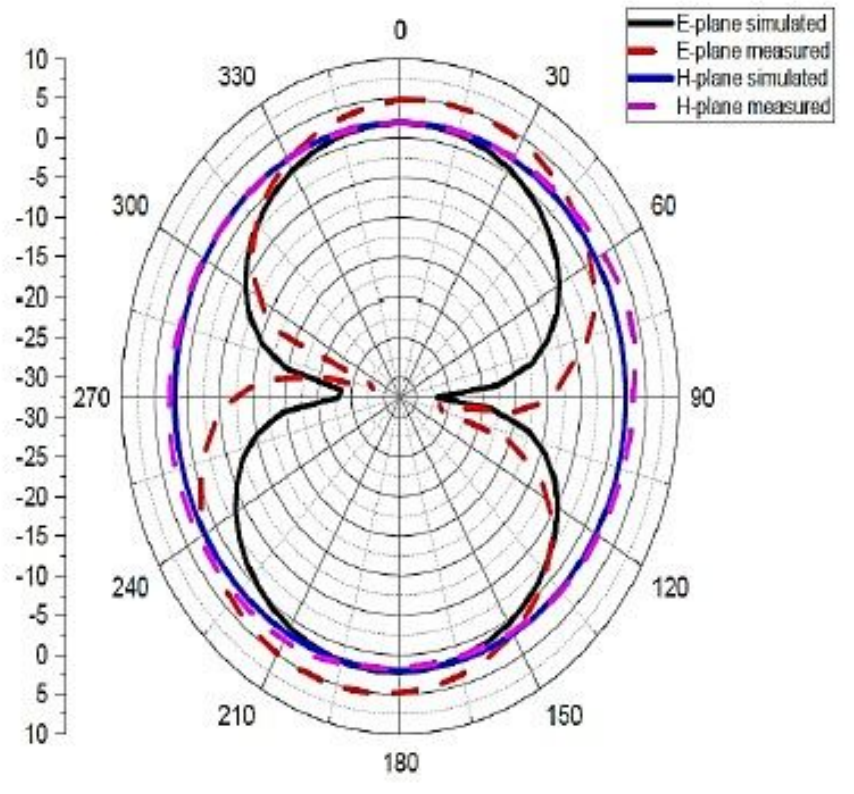

a) $3.16 \mathrm{GHz}$

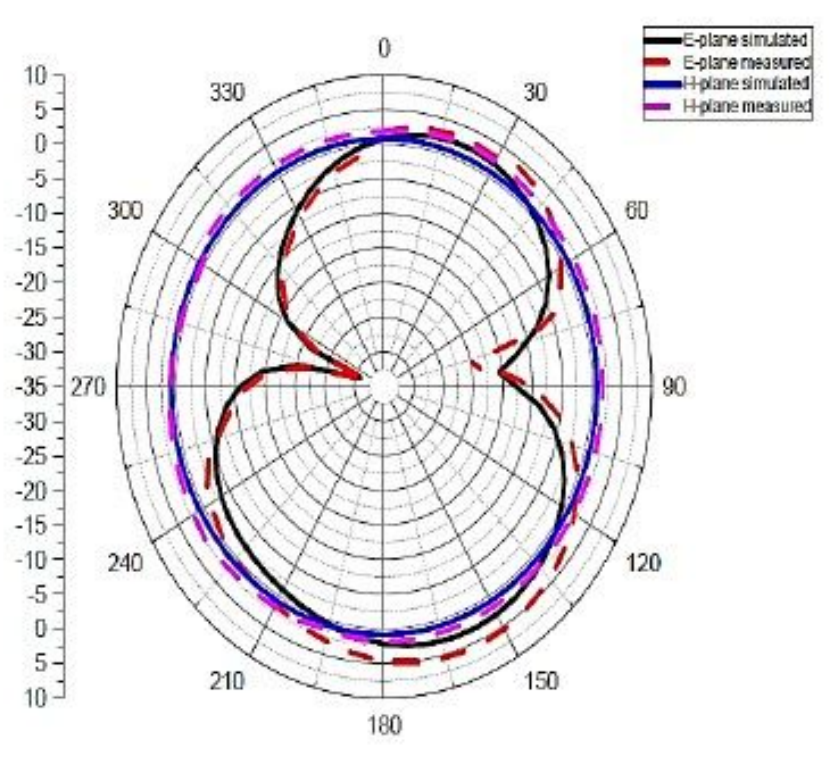

b) $3.82 \mathrm{GHz}$

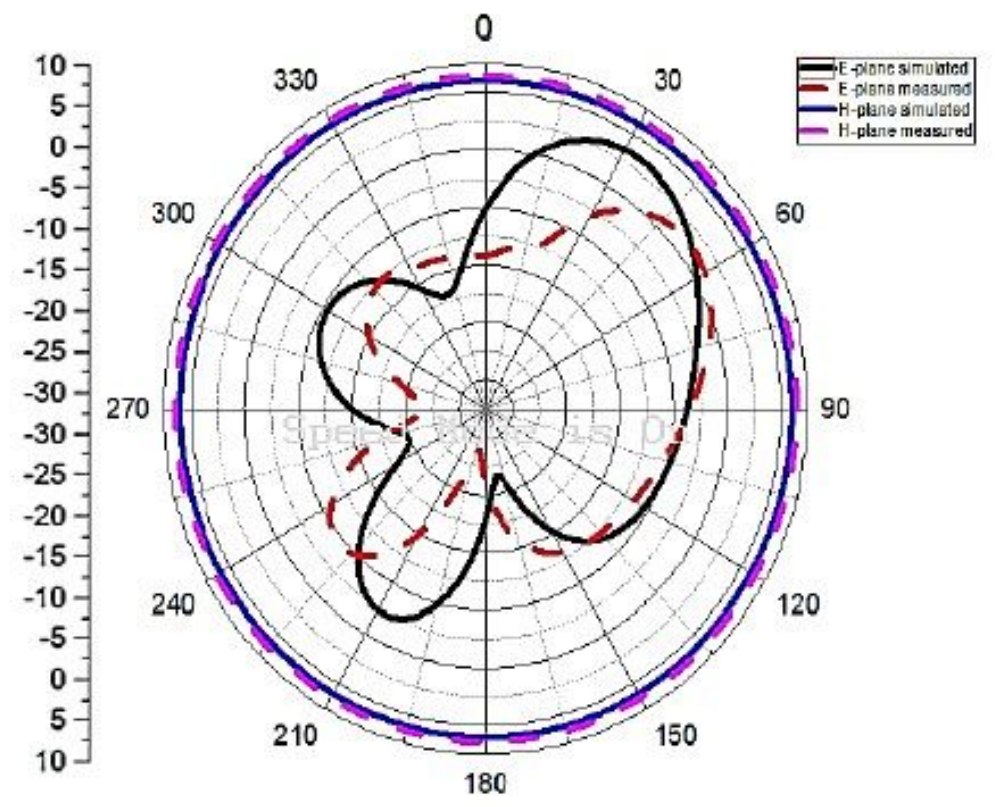

c) $5.41 \mathrm{GHz}$

Figure 15

E-plane \& H-plane pattern (Measured and simulated) at resonating frequencies 


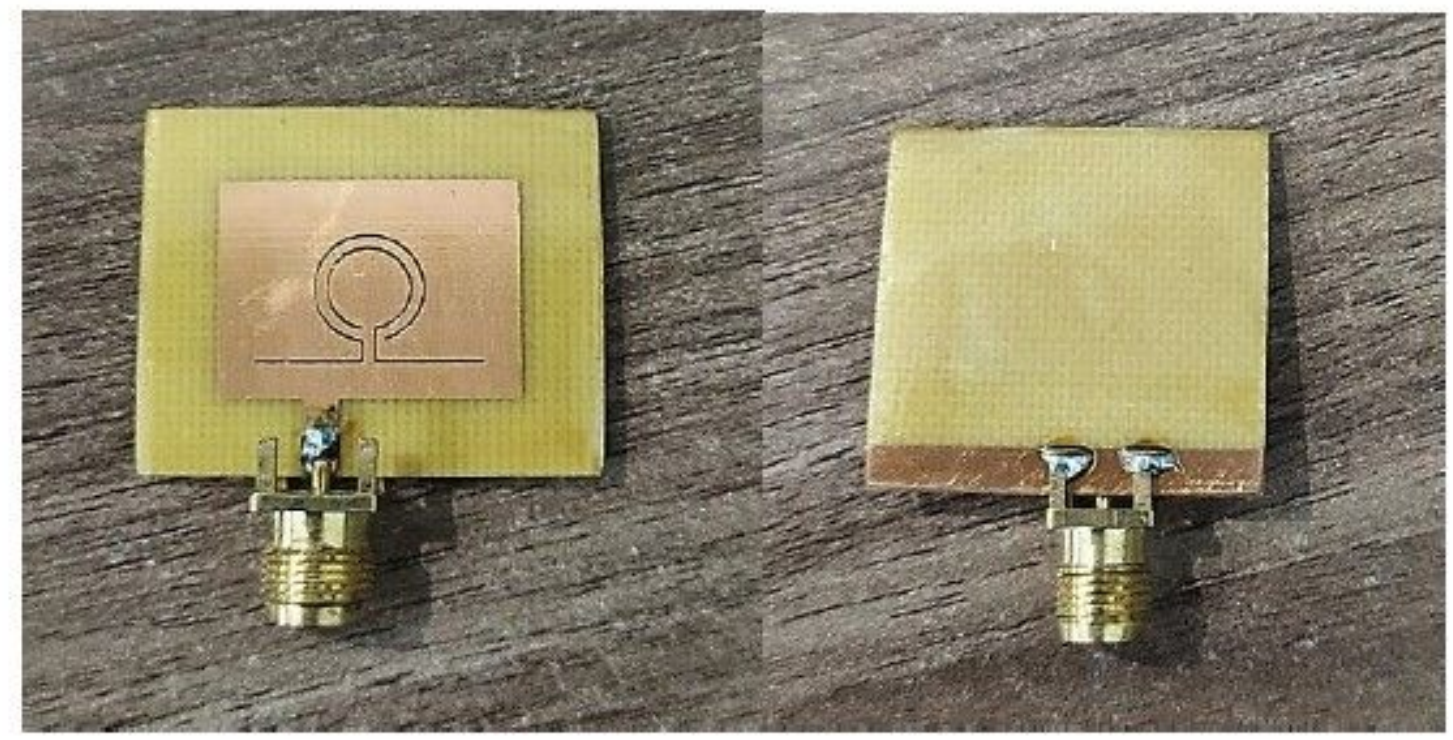

Figure 16

Prototypes of the OCSRR inspired Rectangular antenna

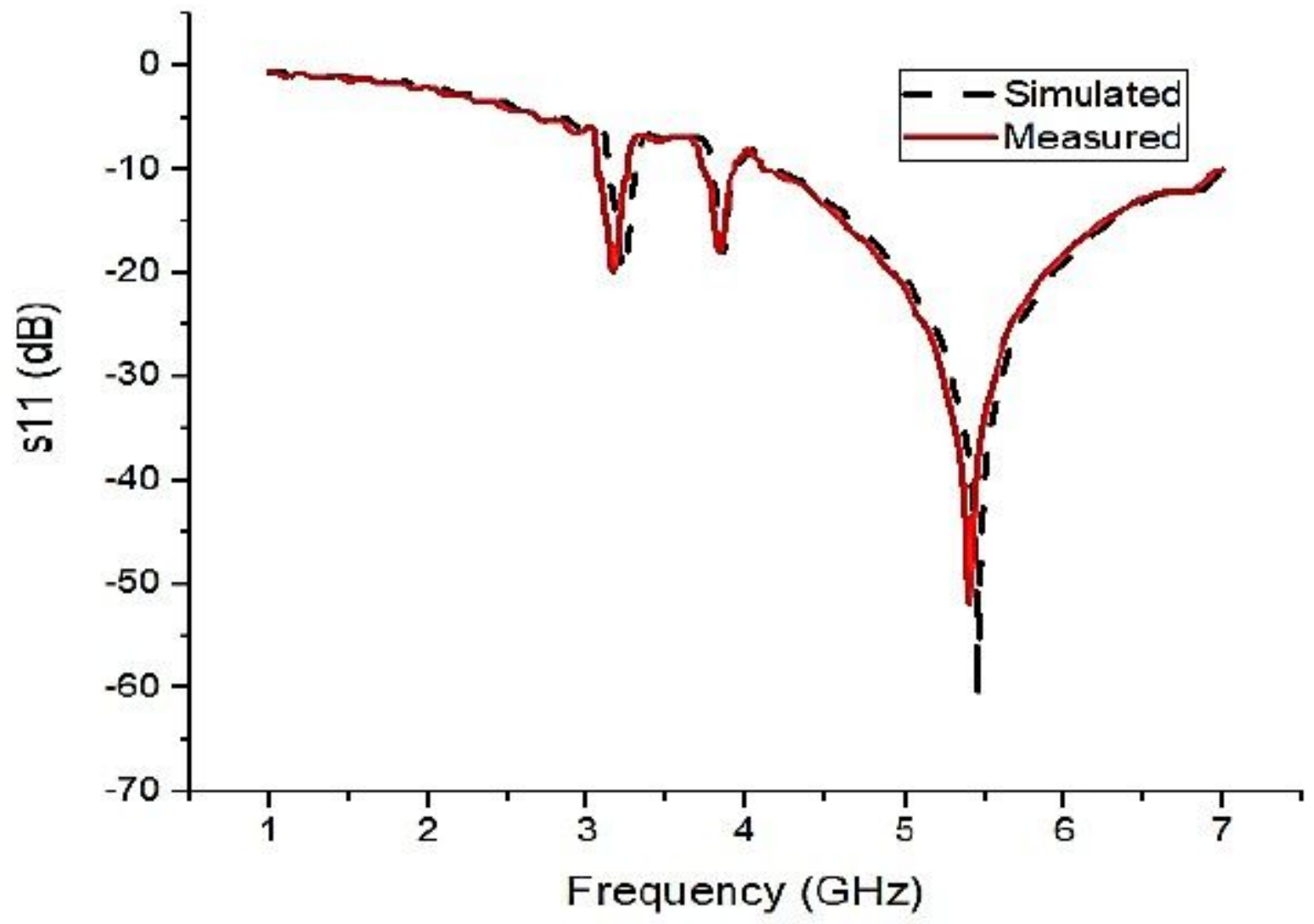

Figure 17

Simulated Vs. Measured S11 


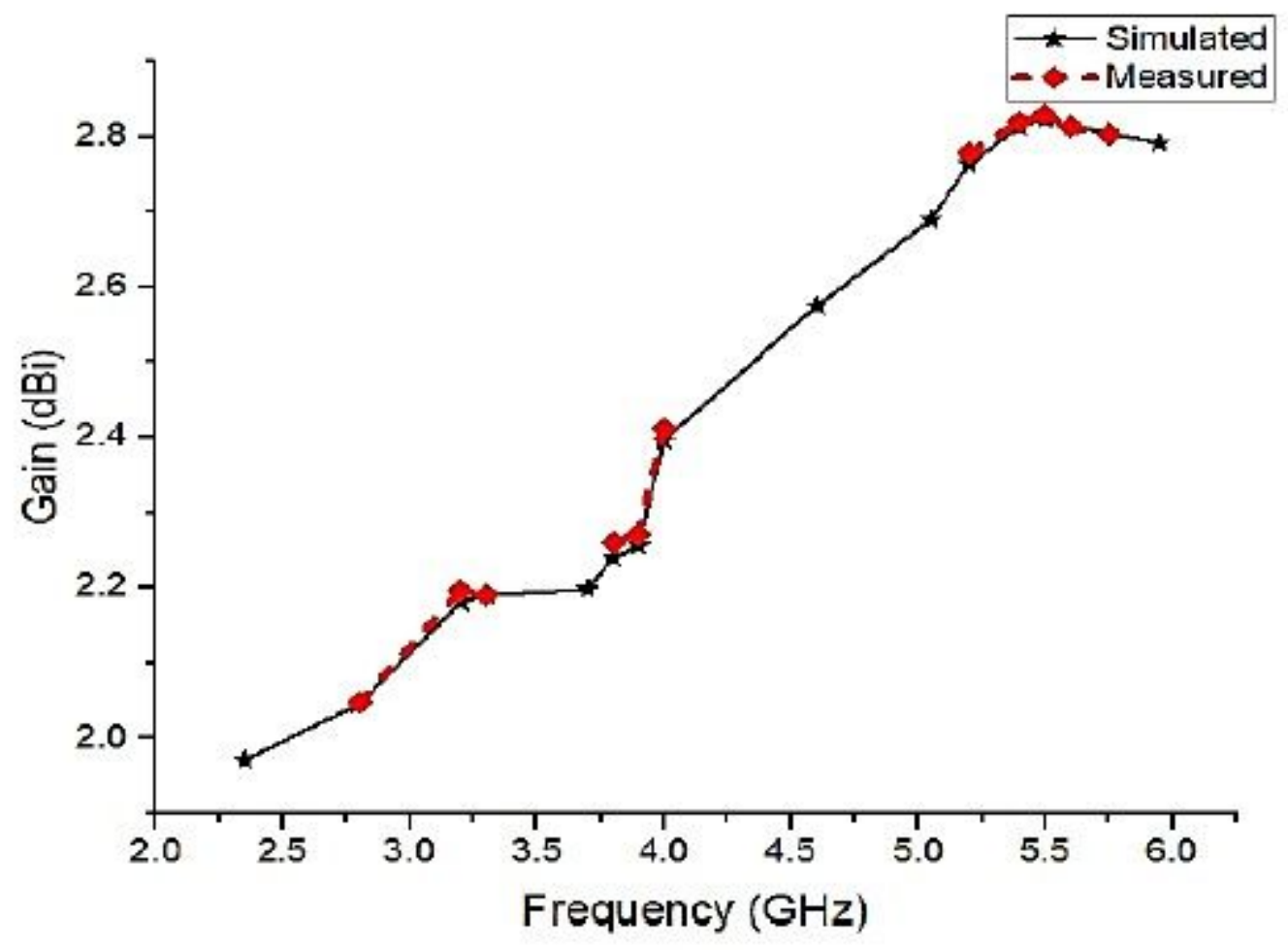

Figure 18

Gain of the OCSRR inspired Rectangular antenna 